\title{
The Myelin Mutants as Models to Study Myelin Repair in the Leukodystrophies
}

\author{
Ian D. Duncan • Yoichi Kondo • Su-Chun Zhang
}

Published online: 7 October 2011

(C) The American Society for Experimental NeuroTherapeutics, Inc. 2011

\begin{abstract}
The leukodystrophies are rare and serious genetic disorders of the central nervous system that primarily affect children who frequently die early in life or have significantly delayed motor and mental milestones that result in long-term disability. Although with some of these disorders, early intervention with bone marrow or cord blood transplantation has been proven useful, it has not yet been determined that such therapies promote myelin repair of the central nervous system. Research on experimental therapies aimed at myelin repair is aided by the ability to test cell replacement strategies in genetic models in which the mutations and neuropathology match the human disorder. Thus, models exist of Pelizaeus-Merzbacher disease and the lysosomal storage disorder, Krabbe disease, which reflect the clinical and pathological course of the human disorders. Collectively, animals with mutations in myelin genes are called the myelin mutants, and they include rodent models such as the shiverer mouse that have been extensively used to study myelination by exogenous cell transplantation. These studies have encompassed many permutations of the age of the recipient, type of transplanted cell, site of engraftment, and so forth, and they offer hope that the
\end{abstract}

Electronic supplementary material The online version of this article (doi:10.1007/s13311-011-0080-y) contains supplementary material, which is available to authorized users.

I. D. Duncan $(\bowtie) \cdot$ Y. Kondo

Department of Medical Sciences, School of Veterinary Medicine, University of Wisconsin-Madison,

Madison, Wisconsin 53706, USA

e-mail: duncani@svm.vetmed.wisc.edu

S.-C. Zhang

Department of Neuroscience and Department of Neurology,

School of Medicine and Public Health, Waisman Center,

University of Wisconsin-Madison,

Madison, Wisconsin 53705, USA scaling up of myelin produced by transplanted cells will have clinical significance in treating patients. Here we review these models and discuss their relative importance and use in such translational approaches. We discuss how grafts are identified and functional outcomes are measured. Finally, we briefly discuss the cells that have been successfully transplanted, which may be used in future clinical trials.

Keywords Myelin mutants · Leukodystrophies · Cell transplantation $\cdot$ Myelination $\cdot$ Oligodendrocyte progenitors

\section{Introduction}

The leukodystrophies are a heterogeneous group of inherited disorders of white matter of the nervous system that affect primarily the central nervous system (CNS), but in some cases they also affect the peripheral nervous system (PNS) [1]. They are serious, progressive disorders of myelin that usually present in infancy or childhood, and more rarely in adulthood, and frequently lead to early death. By definition, there is a failure of development of the myelin or its maintenance. This is reflected in disorders in which there is a lack of myelin in the CNS, as seen in Pelizaeus Merzbacher disease (PMD) or where there is myelin breakdown and axons are demyelinated, such as in Krabbe disease. Given the genetic, clinical, and pathological heterogeneity of the leukodystrophies, the approaches to their treatment will vary. The purpose of this review is to present and discuss potential strategies of myelin repair. In the case of the developmental disorders, notably PMD, the goal is to myelinate axons that had never been ensheathed, while in the demyelinating disorders, the goal is to remyelinate axons. It is not known conclusively whether 
the cellular interactions, molecular cues, and so forth involved in promoting myelination or remyelination will be different in these two situations [2].

Myelin repair will have 2 important functions: 1) it will restore saltatory conduction [3], and 2) it will act as a form of neuroprotection [3,4]. Promotion of myelin repair may use 1 of 2 approaches. In the first approach, endogenous neural stem cells or oligodendrocyte progenitor cells (OPCs) are recruited to divide and differentiate into myelinating oligodendrocytes (OLs) [3]. However, in the leukodystrophies, this approach would be unsuccessful unless it was combined with gene therapy to repair the defect in the OL or target cell. Also, this approach remains theoretical at present, although there is promising data from other experimental myelin disorders that pharmacologic targets exist that can influence OPC differentiation [5]. The alternative is to supply an exogenous source of OPCs or immature OLs to initiate repair. Cell transplantation and endogenous cell recruitment may not be mutually exclusive, however, as the cells are transplanted, they may supply the missing or defective enzyme or protein to endogenous OPCs or OLs [6].

The promotion of remyelination or myelination by an exogenous cell source in disorders in which it is delayed or has failed has been extensively tested in a wide variety of animal models. Two approaches have dominated. In the first, focal areas of demyelination are created by the injection of a myelinotoxic compound, usually lysolecithin or ethidium bromide [7, 8]. As endogenous remyelination usually occurs following such injections, prior focal Xirradiation of the spinal cord kills endogenous OPCs and results in inhibition of endogenous repair and the presence of focal areas of persistently demyelinated axons [9]. Thus, these "plaques" of demyelination are targets for implantation of putative myelin-producing cells. More recently, demyelination created by the ingestion of cuprizone, another myelinotoxic chemical that results in myelin loss in restricted areas of the CNS, which has been used as a model to target exogenous cellular repair [10].

The second or alternative approach to exploring myelin repair is to use animals in which the mutations result in a global failure of myelin development or loss as a result of demyelination. Collectively, these animals are known as the myelin mutants $[11,12]$. Their greatest usefulness may be where they are used as true models of human neurologic disease. The 2 examples of this are 1) the proteolipid protein (PLP) mutants, which are models of PMD, and 2) the mutants of the galactocerebrosidase (GALC) gene, models of Krabbe disease. Although other myelin mutants exist that are used to test the myelinating capacity of exogenous cells, most notably the shiverer (shi) mouse, the models of PMD and Krabbe disease provide great opportunities to study repair in a milieu that faithfully mimics the human condition, and allows the scaling up required for translational application. This review will discuss the use of the myelin mutants in studying myelin repair and how this has led us to the initiation of current and future clinical trials in patients with inherited myelin disorders.

\section{Diseases to be Targeted by Exogenous Cell Therapy}

The leukodystrophies are rare but challenging medical problems, and with few exceptions there are no cures and only supportive therapies (Table 1). The four primary targets are PMD, Krabbe disease, metachromatic leukodystrophy (MLD), and adrenoleukodystrophy (ALD). Exploring therapeutic options for PMD has the advantage of having a number of useful models available, ranging from rodents to a large animal canine model $[9,10]$. In addition, a number of transgenic mice and rat exist that can be useful [13]. The majority $(>60 \%)$ of boys with PMD have a duplication of the plp1 gene $[14,15]$, but no naturally occurring duplications exist in animals. PMD can present as a severe disorder with early death, the so-called connatal form, or the classical form of the disease in which the myelin deficit is not as severe and the life expectancy is greater. Hence, the selection of patients and stage of disease at which transplantation should be performed will be important. A clinical trial of transplantation of neural stem cells into PMD patients is already underway at University of California-San Francisco (Clinical trial NCT01391637). We have begun conducting studies of cell transplantation in the rat transgenic model in which overexpression of the PLP gene results in severe dysmyelination and early death $[16,17]$, similar to the myelin deficient $(m d)$ rat $[18,19]$. This rat, therefore, can model those cases of severe connatal PMD associated with a duplication in the plp1 gene [20]. It will be important to determine whether the milieu of the CNS in PLP over-expression, hence the majority of PMD patients, is receptive to transplanted cells as it is in the missense mutations ( $m d$ rat and the shaking [sh] pup) [21-23].

Krabbe disease is an autosomal recessive demyelinating disorder caused by a genetic deficiency in the activity of a lysosomal enzyme (GALC). Affected OLs and Schwann cells are unable to degrade its substrate, galactocerebroside. Unlike other lysosomal storage diseases, however, storage of galactocerebroside in the myelinating cells does not occur, whereas psychosine, a cytotoxic lipid metabolite, accumulates and appears to kill OLs and Schwann cells, leading to rapidly progressive demyelination. Two clinical phenotypes are known in Krabbe disease: 1) the classical infantile form in which initial symptoms develop a few months after birth and severe motor and mental deterioration progress rapidly leading to death at approximately 2 to 3 years, and 2) the late-onset form in which the onset of 
Table 1 Leukodystrophies

\begin{tabular}{|c|c|c|c|c|}
\hline & Inheritance & Gene defect & Biochemistry & Pathophysiology \\
\hline Metachromatic leukodystrophy & Autosomal recessive & Arylsulfatase A & $\begin{array}{l}\text { Storage of sphingolipid } \\
\text { sulphatide }\end{array}$ & Demyelination in CNS and PNS \\
\hline Krabbe disease & Autosomal recessive & Galactocerebrosidase & Elevated psychosine levels & Demyelination in CNS and PNS \\
\hline Adrenoleukodystrophy & $\mathrm{X}$-linked recessive & $\begin{array}{l}\text { ABCD1 gene encoding } \\
\text { ALD protein }\end{array}$ & $\begin{array}{l}\text { Elevated levels of very } \\
\text { long-chain fatty acids }\end{array}$ & $\begin{array}{l}\text { Demyelination in CNS and } \\
\text { inflammation }\end{array}$ \\
\hline Pelizaeus-Merzbacher disease & $\mathrm{X}$-linked recessive & plp1 & Absence of PLP or decrease & $\begin{array}{l}\text { CNS dysmyelination, PNS } \\
\text { involvement rare }\end{array}$ \\
\hline Canavan disease & Autosomal recessive & Aspartoacylase & $\begin{array}{l}\text { Elevated } \mathrm{N} \text {-acetylaspartic } \\
\text { acid level }\end{array}$ & Spongy degeneration of CNS \\
\hline $\begin{array}{l}\text { Vanishing white matter disease } \\
\text { (childhood ataxia with } \\
\text { central hypomyelination) }\end{array}$ & Autosomal recessive & eIF2B & Increase CSF glycine & $\begin{array}{l}\text { Hypomyelination; cyst/cavity } \\
\text { formation in cerebral white } \\
\text { matter }\end{array}$ \\
\hline Alexander disease & $\begin{array}{l}\text { Unclear (de novo } \\
\text { mutations) }\end{array}$ & $\begin{array}{l}\text { Glial fibrillary acidic } \\
\text { protein }\end{array}$ & - & $\begin{array}{l}\text { Inclusion body (Rosenthal fibers) } \\
\text { in astrocytes }\end{array}$ \\
\hline Refsum disease & Autosomal recessive & $\begin{array}{l}\text { phytanoyl-CoA } \\
\text { hydroxylase (PAHX) } \\
\text { or peroxin } 7 \text { (PEX7) }\end{array}$ & $\begin{array}{l}\text { Accumulation of phytanic } \\
\text { acid in blood, fat, neuron }\end{array}$ & Hypomyelination \\
\hline $\begin{array}{l}\text { Cerebrotendinous } \\
\text { xanthomatosis }\end{array}$ & Autosomal recessive & Sterol 27-hydroxylase & $\begin{array}{l}\text { Accumulation of cholesterol } \\
\text { and cholestanol in CNS } \\
\text { and tendon }\end{array}$ & White matter axonopathy \\
\hline
\end{tabular}

$\mathrm{ALD}=$ adrenoleukodystrophy; $\mathrm{CoA}=$ coenzyme $\mathrm{A} ; \mathrm{CSF}=$ cerebrospinal fluid; $\mathrm{CNS}=$ central nervous system; $\mathrm{PLP}=$ proteolipid protein; $\mathrm{PNS}=$ peripheral nervous system

clinical signs varies from 3 months to more than 40 years of age, and the neurological deterioration progresses slowly in general. Importantly, the majority of patients with Krabbe disease are infants, and they succumb early in life to severe neurological symptoms [24].

MLD is an autosomal recessive disorder resulting from a mutation in the arylsulfatase A gene, which leads to profound demyelination of the CNS and PNS. MLD can present as an infantile, juvenile, or adult onset disorder and the late infantile onset cases ( $<2$ years) are likely the most relevant target for cell therapy. The severe involvement of the PNS in MLD and in Krabbe disease provides greater challenges in developing remyelinating strategies compared to PMD. A knockout of the arylsulfatase gene has been generated [25], but there is only scattered demyelination in the nervous system of the mouse, which nonetheless appears to be corrected in symptomatic mice by hematopoietic cell transplants that were transduced to overexpress the gene [26]. However, the limited demyelination makes the knockout mouse less useful to test exogenous cell-induced remyelination. Transplantation of adult mouse neural stem cells into the MLD knockout mouse brain resulted in improvement in the biochemical defect, but no differentiation of cells into OLs [27], probably because the lack of demyelination and the need for OLs.

ALD, which is the most common leukodystrophy in children, results from a mutation in the peroxisomal membrane protein gene ABCD1 [28, 29]. The disease is striking in its phenotypic variation. The early onset, childhood cerebral form has profound subcortical demyelination associated with marked inflammation [30]. In contrast, the adult onset phenotype (adrenomyeloneuropathy) has notable long-tract degeneration in the spinal cord and no prominent demyelination $[30,31]$, hence it is an unlikely target for myelin repair. Attempts to generate an animal model of childhood ALD using a mouse knockout strategy have failed to yield a model with similar pathology [31]. An alternative model in which OLs are targeted that could be used to examine cell-based remyelination relative to ALD is the peroxin-5 conditional knockout mouse [32]. Peroxin-5 is involved in transport of proteins into peroxisomes, and its deletion results in a mouse with a progressive, late onset neurologic disease associated with demyelination, axon loss, and inflammation [32]. In addition, the mouse had an accumulation of very long chain fatty acids in the brain, a hallmark of ALD. It could, therefore, serve as a surrogate model of ALD to test exogenous cell remyelination, but axon loss may be an impediment.

Two other leukodystrophies with extensive white matter changes may be considered for cell-based therapy. The infantile form of Alexander disease has profound frontal lobe myelin pathology [1]. The disease has been found to result from mutations of the glial fibrillary acidic protein gene [33], but attempts to create an animal model using 
knockout or knockin strategies have failed to produce any myelin changes [33]. The final disease to be considered is Canavan disease, which results from mutations in the aspartoacylase gene, leading to profound vacuolation of white matter as is found in a knockout of the gene [34, 35] and in a point mutation in the rat model [36]. However, there is little or no evidence that the white matter change leads to significant demyelination, hence promoting remyelination would not seem to be a useful therapeutic strategy. A lack of demyelination in this disease in the presence of extensive white matter vacuolation is not unique. Mitochondrial DNA mutations in a canine disorder [37] and in Kearns-Sayre syndrome in humans [38] lead to profound myelin vacuolation, but little demyelination. Transplanting OPCs into the aspartoacylase knockout mouse has shown that they differentiate into mature OLs [39] and transplanted cells may therefore be a source of the missing enzyme to cross-connect endogenous cells. Other, newer and less well-characterized developmental disorders of myelin exist that may be future targets for remyelination therapy. Vanishing white matter disease is a more recently recognized white matter disorder that might be considered, yet axonal loss can be severe, perhaps limiting the chances of successful myelin repair [40].

A key feature of the leukodystrophies in regard to remyelination is the degree of axon loss in each. Although they are all primary myelin diseases, there is almost always some axon loss, as pure demyelinating disorders with no loss of axons is rare. Thus, in PMD some axon loss has been reported [41] as it has in Krabbe disease [24] and ALD [30, 31]. However the degree of axon degeneration may not be significant in terms of producing long-term disability, as is thought to happen in multiple sclerosis (MS) [42].

\section{Myelin Mutants used as Models of Myelin Repair}

The myelin mutants are a heterogeneous collection of animals, some of whose mutations make them models of individual human leukodystrophies (Table 2). Others have no known human analog or their mutation is unknown, yet they can provide opportunities as models with which to study exogenous cell-based remyelination. The largest and most homogenous group is those with disorders in the plp1 gene, which are models of PMD. However, the most commonly used myelin mutant in transplant experiments is the shi mouse, which has a mutation in the myelin basic protein $(M B P)$ gene, but it is not a model of human disease. All of these mutants have predominantly developmental defects of myelination. In contrast, myelin mutants also exist in which there is a loss of myelin (i.e., demyelination). Collectively, therefore, these mutants offer a broad range of opportunities to study myelin repair.

\section{The PLP Mutants}

These mutants form the largest group of myelin mutants and are models of the human disorder PMD. The $p l p l$ gene is located on the $\mathrm{X}$ chromosome, hence the mutations are inherited as X-linked recessive disorders. Mutations in the plp1 gene have been found in mice (the jimpy $[j p]$ mouse and its allele [jpmsd]), the rat (myelin deficient $[m d]$ rat), the dog (the shaking pup [sh] pup), and in the pig (mutation not defined) [12]. In regard to cell transplantation, only the $m d$ rat and the sh pup have been used in any detail. The $m d$ rat has a point mutation in the third exon of the plpl gene [43] and develops tremors at approximately 10 days of age, seizures at 18 to 20 days, and it dies at 24 to 25 days [ 18 , 19]. There is practically no myelin throughout the CNS, with a reduction in mature OLs through their early apoptosis [44]. The scarce myelin sheaths present in the md rat lack the normal double leaflet intra-period line [45]. Transplants into the $m d$ rat have been performed from postnatal day (P) 0 to P7. This allows transplanted cells from 2 to 4 weeks to divide and migrate, integrate and myelinate axons before the demise of the rat. We have also transplanted cells into fetal $m d$ rat pups following laparotomy and injection through the uterine wall, but this is a challenging and time-consuming endeavor [46]. A longer lived strain of the $m d$ rat has been reported that could be of use in studying longer post-transplant time points, and data from such an animal is described as follows [47]. However, this rat is no longer available. The usefulness of the $m d$ rat is that it is an excellent model in which to test the myelinating capacity of cells transplanted as either allografts or xenografts, but its early death limits the time that grafted cell function can be monitored. The presence of extensive myelin formation and determination that the myelin is PLP positive are clear indicators (as in shi with MBP) that the myelin has resulted from the transplanted cells.

The sh pup is a canine mutant, first described by Griffiths et al. [48, 49] in Glasgow in 1981. It is inherited as an Xlinked recessive with a point mutation in the second exon of the plp1 gene [50]. Affected pups develop a notable tremor at 6 to 10 days of age. They are never able to ambulate, but they can survive far beyond 2 years if hand raised. They develop seizures from 2 months that can be controlled with anti-convulsants. The myelin deficiency is not as severe as in the $m d$ rat, but their usefulness lies in their longevity and the greater size of the CNS compared to rodents that allows a "scaling-up" of cell therapy toward trials in PMD. A magnetic resonance image (MRI) of the canine brain has shown clear differences in myelination between wild-type and mutant dogs [51]. Myelin in the sh pup is weakly PLPpositive, so the proof of myelinating capacity of transplanted cells comes from the increased density of myelin compared to nontransplanted animals [52]. 


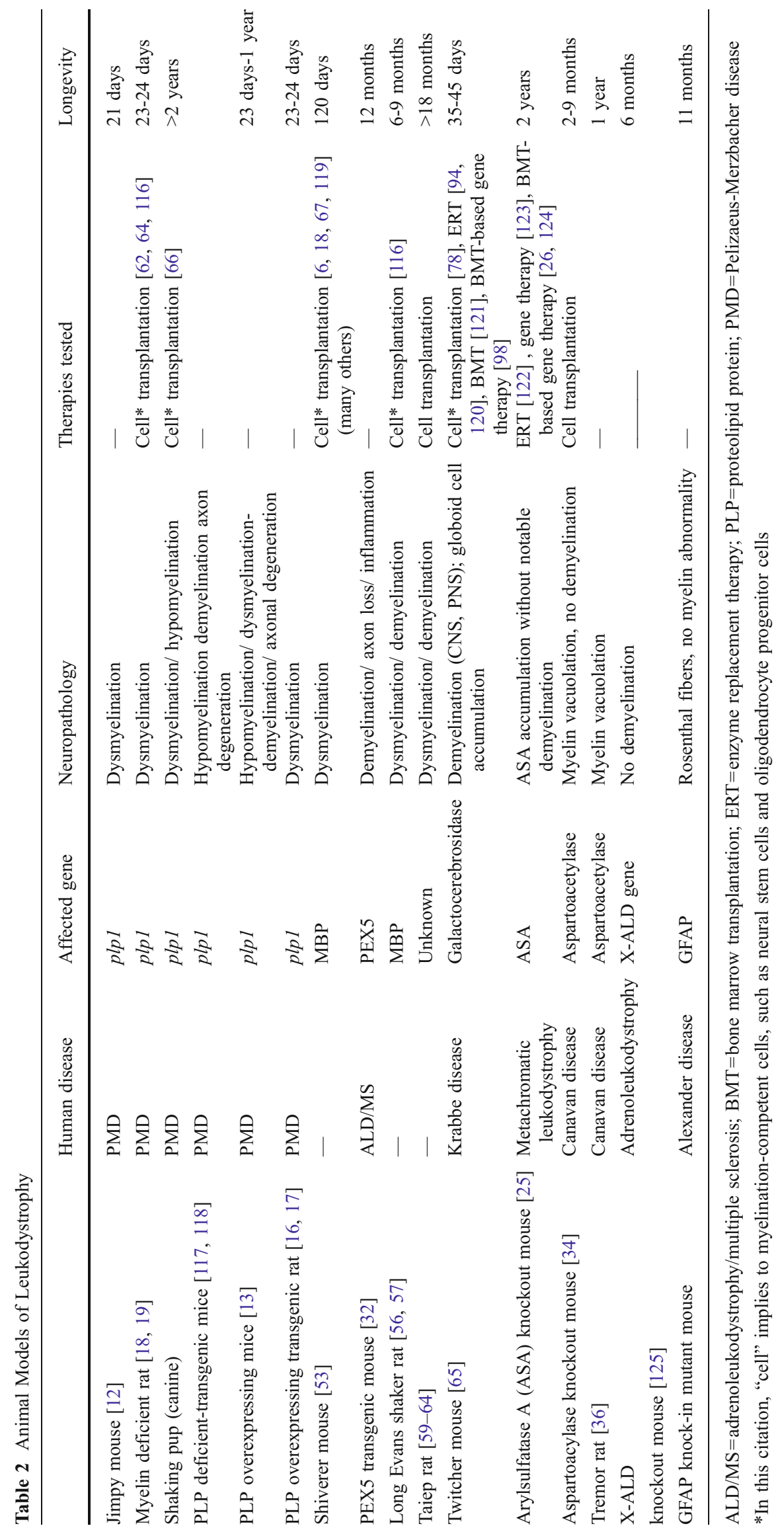




\section{The MBP Mutants}

Shiverer (shi) is an autosomal recessive mutant in which there is a major deletion in the $m b p$ gene resulting in a severe reduction of myelin in the CNS [53]. Ultrastructural analysis demonstrates that the scattered, thin myelin sheaths that are present lack a major dense line [53]. Homozygous mice have a notable tremor from 12 days of age forward, and develop seizures at approximately 30 days of age, with death at approximately 120 days. The generalized absence of myelin makes the analysis of transplant-induced myelination straightforward. First there is significantly more myelin than in controls, and the myelin is MBP positive [6, 54, 55]. Further confirmation that this myelin is not endogenous can be seen on electron microscope (EM), in which the myelin has a major dense line and a thicker sheath than compared to the thin myelin sheaths of the host [55].

The Long Evans shaker (les) rat is also an MBP mutant, but it has been used much less than the shi mouse in myelin repair research, and nonetheless it offers additional opportunities to the shi. The mutation is also autosomal recessive and results from the insertion of a retrotransposon into intron 4 of the $m b p$ gene, leading to a failure in gene transcription and hence failure of production of the MBP [56]. As with the shi, the les rat has practically no myelin throughout the CNS, but a striking difference is that the spinal cord initially has myelin, especially in the ventral column, but this is all lost by 4 to 6 weeks of age [57]. Thus, the les rat has features of both dysmyelination and demyelination. Like the $s h i$, it develops seizures from 4 to 6 weeks of age, but lives much longer if carefully reared, and it can survive for as long as 9 months of age or even longer in rare cases. The loss of myelin is associated with a marked microgliosis [58]. The longevity of les and the larger nervous system provides some advantages to shi.

\section{The taiep Rat}

The taiep is an autosomal recessive mutant found on a Sprague Dawley background [59]. It is a unique myelin mutant that initially demonstrates hypomyelination, and then severe demyelination of white matter in the brain, optic nerves, and the fasciculus gracilis and corticospinal tract of the dorsal column of the spinal cord [59]. The early failure of normal myelination and subsequent demyelination result from the progressive accumulation of microtubules in OLs $[59,60]$. This results in a disturbance in the polarity of microtubules and a disruption in the transport of molecules and mRNAs that utilize the microtubular network within the cytoplasm of OLs [61-63]. We have mapped the taiep gene to rat chromosome 9 [64] and are continuing efforts to identify the gene and its mutation. The usefulness of the taiep is that it lives for as long as 2 years of age with progressive neurologic dysfunction, and it can be used to test exogenous cell repair of demyelinated axons unlike that in shi or the plp1 mutants, and also in older recipients than is possible with other rodent mutants.

\section{The twitcher Mouse}

The twitcher (twi) mouse is a model of Krabbe disease, also known as globoid cell leukodystrophy [65]. The mouse lacks the GALC enzyme due to a nonsense mutation in the GALC gene [66]. Affected twi mice (on B6 background) develop a tremor at $\mathrm{P} 10$, fail to thrive, and develop rapidly progressive neurological dysfunction with paresis leading to hind limb paralysis after P30. They do not survive beyond 45 days. However, an extended lifespan has been reported when its genetic background is altered $[67,68]$. The neuropathology is characterized by the infiltration of periodic acid schiff (PAS)-positive macrophages (so-called globoid cells) concomitant or prior to demyelination both in the white matter of CNS and PNS. Demyelination progresses in an orderly manner as myelin develops in the white matter [69].

In addition to the twi mouse, other animal models of Krabbe disease that have spontaneous mutations in the GALC gene have been identified. These include dogs [70, 71], cats [72], and the rhesus monkey [73]. Although none of these have been used to study myelin repair, the canine and primate models as large animal models, provide the opportunity to scale-up remyelination therapies.

\section{Outcome of Cell Grafting in the Myelin Mutants}

Historically, the outcome of glial cell transplantation into the myelin mutants was assessed primarily on the myelin produced. Thereafter, evaluation of cell survival, migration, division, and so forth were explored. Finally, the potential for cell grafting leading to functional improvement has been studied.

\section{Myelination}

The first transplants in the shi mice or $m d$ rats were performed to test whether cells could myelinate host axons on transplantation and not as a test for future therapies. Thus, the initial studies provided proof-of-principle only that this was feasible. The shi transplants were carried out in the laboratory of the late Madeleine Gumpel, Salpetriere, Paris, and on the $m d$ rat by 1 of us (IDD) at the University of Wisconsin-Madison in the 1980s. These experiments showed that there was focal myelination in the brain of shi mouse with some migration of cells from the site of implantation of fragments from the olfactory bulb [74, 75]. The myelin was MBP positive and had a normal major 
dense line [76]. In the $m d$ rat, transplantation of cell suspensions from either CNS or PNS (Schwann cells) into the spinal cord resulted mainly in focal myelination in the dorsal column, which was either PLP-positive in the case of CNS suspensions, or P0-positive in the case of Schwann cells [21]. The myelin produced by CNS grafts had a normal intraperiod line. Migration of cells away from the site of transplantation, with myelin present in the lateral column was seen in 1 recipient (Fig. 1a). Since these early reports, numerous other studies have confirmed the ability to generate large, yet predominately focal areas of myelin in shi (MBP-positive) and the $m d$ rat (PLP-positive) (Fig. 1). In the case of spinal cord transplantation, visual inspection of the spinal cord on removal from the recipient may show an obvious white "streak" in the dorsal or ventral column, which corresponds to an area of myelin made by the transplanted cells (Fig. 2). In the $m d$ rat, in some cases almost the entire dorsal column can be myelinated at the site of engraftment [22, 23, 77]. In both the shi and $m d$ rat, myelin made by transplanted cells is characteristically thin, similar to that seen in endogenous remyelination. However in some instances myelin made by the transplanted cells is normal thickness, possibly relating to time post-grafting (Fig. 1d) [52, 55]. Repair of a myelin deficiency is also required by some axons in the grey matter. In $m d$ transplants and in the sh pup, this has been documented and it appears that the degree of myelination is equivalent to that seen in normal grey matter (Fig. 1f, g).

Many, if not most, of the work previously cited is from the transplantation of cells into the neonate. This would seem to match the likely scenario well in treating children with leukodystrophies. However, transplantation of OPCs has also been carried out in adult shi mice [78-80] and in the sh pup [52] with successful myelination. This is not always true in all of the myelin mutants, as we and others have had little success in transplanting OPCs into the CNS of the taiep rat. If, however, the white matter is "primed" to become mildly inflammatory, transplanted cells myelinate taiep axons [81]. The question of stability of myelin made by transplanted cells is important, as this is a prerequisite in translational use. The shi mouse is usually limited by the shortened lifespan of the mouse, but grafts and their myelin have been noted to survive for as long as 120 days. Division of human glial restricted progenitors in shi has
Fig. 1 Transplantation of myelin-producing cells into the myelin deficient $(m d)$ rat. Eight weeks after transplanting a mixed glial cell preparation from wild-type spinal cord, there was extensive myelination in the dorsal and ventral columns, with a small patch of myelin in the ipsilateral lateral column (arrow). (a) Details of the myelination of the dorsal (b) and ventral (c) column in adjacent sections are shown on higher power. Myelination of the complete ventral column on the left side of the cord enlarges it to almost twice the size of the nonmyelinated right column (c); the complete myelination and nonmyelination in these areas, respectively, are shown in (d) and (e). In addition, the left ventral grey matter $(* \mathbf{c})$ is appropriately myelinated compared to the right side ( $\mathbf{f}$ and $\mathbf{g}$, respectively)
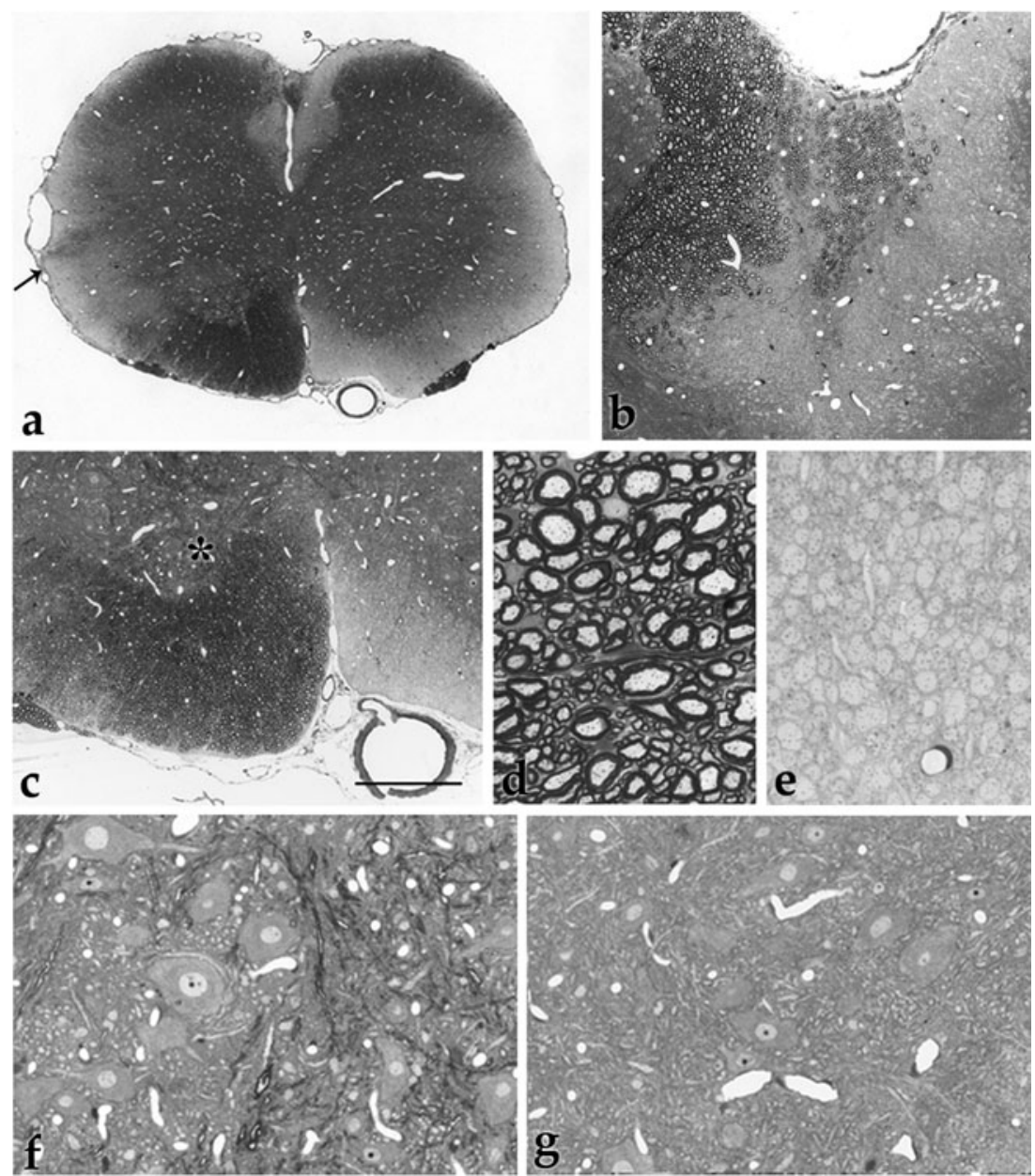

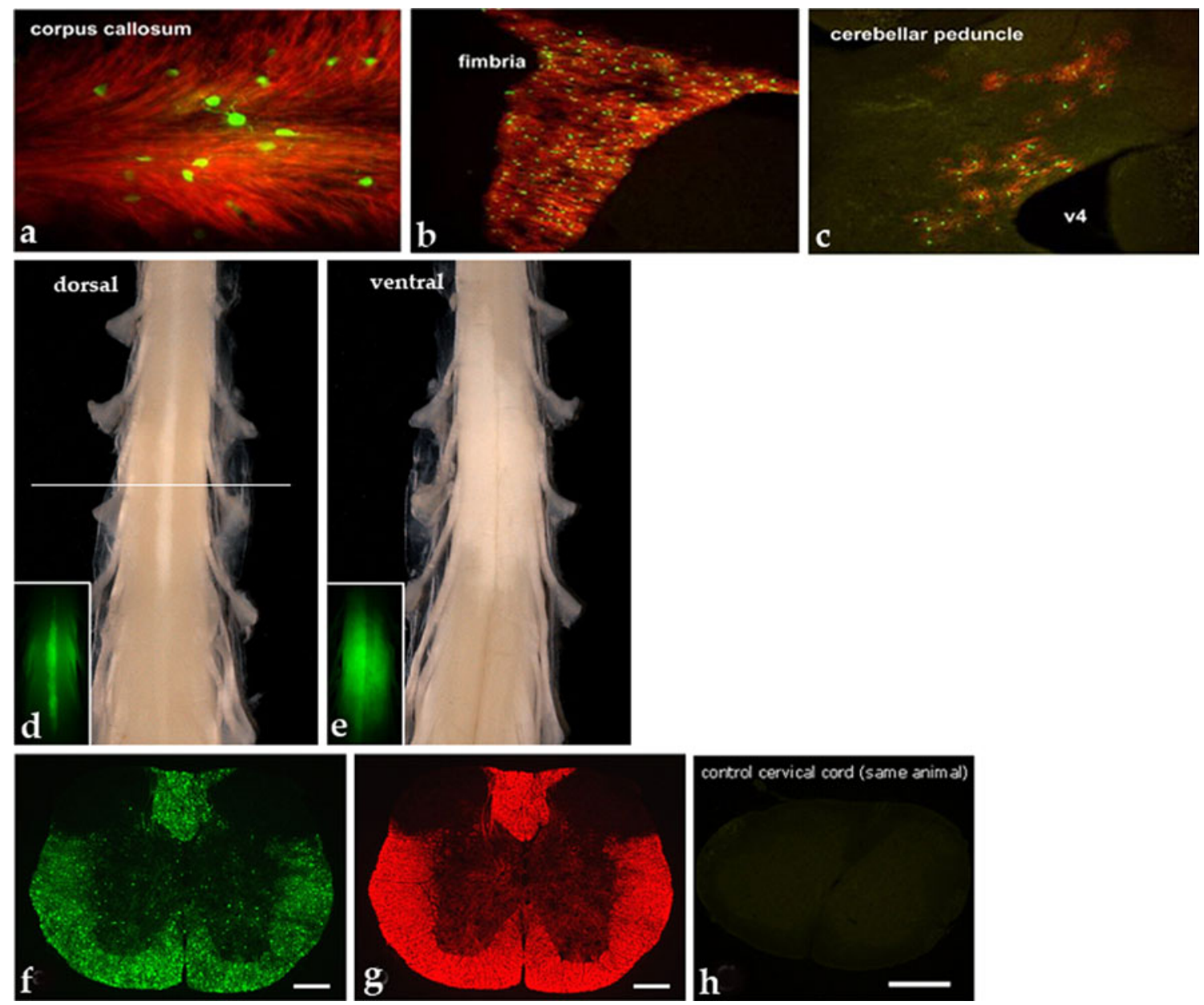

Fig. 2 Myelination of the brain and spinal cord in the shiverer (shi) mouse. A shi mouse at 120 days of age that was transplanted at $\mathrm{P} 0$ in the brain with 2',3'-Cyclic-nucleotide 3'-phosphodiesterase (CNP)green fluorescent protein (GFP) transduced oligodendrocyte progenitor cells derived from oligospheres, and P21 in the spinal cord. Three areas from the brain (a-c) show GFP-positive cells (yellow/green) scattered throughout the brain associated with myelin basic protein (MBP)-positive myelin (red). The spinal cord when viewed both from the dorsal (d) and ventral (e) views shows a white strip (d) and broad

been demonstrated by Ki67 labeling [55]. However, the ongoing myelination in these transplants was not ascribed to an increase in the production of myelinating OLs by the transplanted cells [55]. In more recent work by Windrem et al. [55] in which the global repair extended the lifespan of recipient shi mice there is survival of myelin as long as 1 year of age and longer. We have also found evidence of cell and myelin survival, 6 and one-half months after transplantation in the sh pup [52]. This longevity has been extended further in a transplant study in the taiep rat. Transplantation of OPCs derived from lacZ-transduced oligospheres resulted in survival of cells in the dorsal column, 18 months after injection, with widespread myelination by the transplanted cells (Fig. 3) (Zhang and Duncan, unpublished data). white band (e) that marks myelin made by the transplanted cells. The insets show the fluorescent signal that corresponds with myelin deposition. The white line through the cord (d) marks the areas of the cord shown in transverse section in (f) and (h). In (f), GFP-positive cells are seen at high density in the white matter and also in appropriate numbers in grey matter. These cells have completely myelinated the cord (g) compared to a segment from the cervical cord of the same mouse, which is MBP negative (h)

Although these results have been promising and illustrative of the potential of cell therapy in the leukodystrophies, the need for more global myelin repair is essential. In this regard, 3 studies in the shi mouse and 1 in the sh pup standout. In the first of these, Mitome et al. [82] transplanted green fluorescent protein (GFP)-transduced neural stem cells into the lateral ventricle(s) of neonatal shi mice and the cisterna magna, and examined the mice 12 weeks later. They showed extensive spread of the cells throughout the putative white matter of the brain that was MBPpositive, with the spread of MBP-positive myelin, into the cervical spinal cord. This was the first real evidence of extensive repair in shi. In the second study, we transplanted OPCs into the brain at P0 to P1 and into the dorsal column of the thoracolumbar spinal cord of the same shi mice 

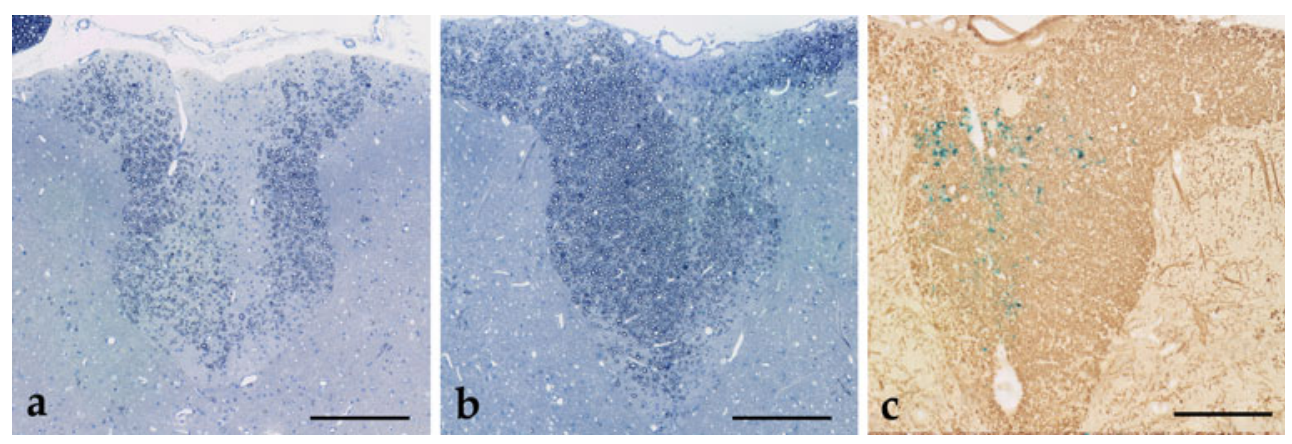

Fig. 3 Long-term survival of grafted cells. Sections from the thoracic cord, dorsal column of a 1 and one-half-year-old taiep rat, transplanted at 8 days of age with lacZ-positive oligodendrocyte progenitor cells derived from oligospheres. In (a) a few millimeters from the site of injection, it can be seen that the fasciculus gracilis (fg) and cortico- spinal tracts are poorly myelinated. In contrast, at the site of injection (b), almost the entire dorsal column is myelinated. In a myelin basic protein (MBP)-stained section close to the site of the transplant, the dorsal column appears well-myelinated, and notably, a patch of lacZpositive cells is present. (a, b) toluidine blue; (c) MBP
3 weeks later [6]. At 120 days, the mice were examined and GFP-positive OPCs were found to have extensively migrated throughout the brain, associated with MBPpositive myelin patches, and across the entire spinal cord at the site of injection (Fig. 2). The most compelling evidence of global repair in $s h i$, however, comes from the study of Windrem et al. [55]. In this study, they generated a shi-rag2 knockout mouse into which they transplanted human fetal glial precursors. These mice were transplanted at P0 with a total of 300,000 cells divided between 5 injection sites, with 4 that were bilateral injections in the anterior and posterior corpus callosum, and the fifth into the cerebellar peduncle. The first striking evidence from these mice was the prolonged survival of $21 \%$ of the mice for as long as 1 year of age, with improvement in their neurologic dysfunction, in particular their ambulation and lessened seizure frequency. Examination of the brains of these mice showed remarkable dispersion of GFP-positive cells that increased with time. The human origin of these cells was confirmed with an antibody to human nuclear antigen associated with MBP reactivity throughout the brain. Extensive myelination was also seen in the spinal cord and approximately $80 \%$ of the axons in the upper cervical and corticospinal tract were myelinated. This study unequivocally demonstrated the power of exogenous cell therapy, albeit in the mouse. It is clear that multiple sites of transplantation are required, yet it is not clear why only $20 \%$ of the mice displayed this widespread integration of human cells and survived.

Glial cell transplantation in the sh pup has also been illustrative of the degree of myelination that can be achieved from focal transplantation. Indeed the study of Archer et al. [52] was the first to demonstrate that myelin made by transplanted cells myelinate areas of the size comparable to some MS plaques in a large animal model, hence this could be of clinical significance. Transplanting fetal canine glia into the spinal cord resulted in almost complete myelination of the dorsal column, unilaterally in the lateral column and complete myelination of the ventral columns (Fig. 4). This transplant-induced myelin was found along $20 \mathrm{mms}$ of the spinal cord and was 10 times the volume achieved in the $m d$ rat shown in Fig. 1. An outstanding goal will be to use the sh pup to follow myelin repair in vivo using MRI.

\section{Tracking Cells and Their Fate After Transplantation}

Although a number of methods have been used to label cells prior to transplantation, the 2 methods most frequently used are to transduce the cells to express a reporter gene, usually $\beta$-galactosidase (lacZ) or GFP $[6,55,83]$. In the case of lacZ, the spinal cord or brain at the site of transplantation is incubated overnight in $\mathrm{X}$-gal solution [23]. In 24 hours, a blue reaction product is seen at the site, which will frequently overlap with a white patch seen grossly prior to X-gal staining [23]. More recently, GFP has become the standard method of tracking cells and has some advantages over lacZ, as cell tracking is performed by shining a fluorescent light on the transplanted tissue and positive areas can be selected for further studies (Fig. 2). As with lacZ, the areas of positive fluorescence usually overlap with a patch of myelin (Fig. 2). However, in the brain, given the localization of white matter compared to the spinal cord, it is difficult to follow cells without first trimming the brain into slices (Fig. 2). In the case of xenografts, in most instances human cells grafted into animal models, human-specific antibodies, such as human nuclear antigen are extremely useful in following cell survival and migration (Fig. 5). Most recently, GFP gene transduction of human neural precursors has been shown to track long distance migration of cells when transplanted into focal demyelinated lesions of the nude mouse spinal 
Fig. 4 Scaling up of transplantinduced myelination. Thoracic spinal cord from a 9-week-old shaking (sh) pup transplanted at 1 week of age with a glial cell suspension from the brain of an E-45 day fetal pup. More than $5 \mathrm{~cm}$ from the transplant site, the white matter appears poorly myelinated (a) and on higher power contains only scattered myelinated fibers $(\mathbf{c})$. At the site of injection (b), a large part of the dorsal column is myelinated, as are the ventral columns and the deep part of the right lateral column (arrow). On higher power of the ventral column, all axons are myelinated (d)
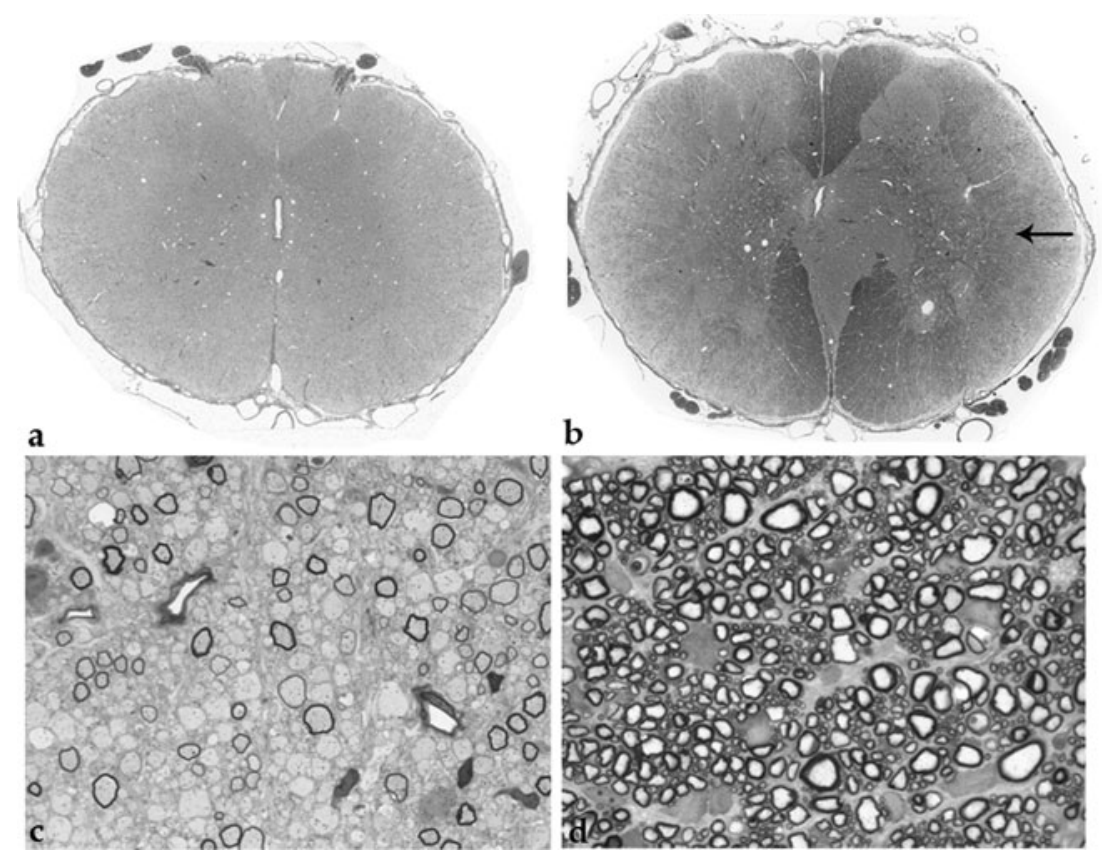

cord [83]. The migration, well beyond the lesion site, suggests that transplanted cells do have the ability to migrate through normal white matter [83].

These transplant experiments have also provided information on cell survival and division after engraftment. Although there has been little documentation of the death of transplanted glia in these mutants, the number of pyknotic nuclei at 4 and 24 hours after transplantation of OPCs into the dorsal column of $m d$ rats was found to be approximately $56 \%$ and $25 \%$ at each time point [84]. This significant cell death is typical of what occurs following any neural cell transplant and success of the transplant likely means that surviving cells must divide. Autoradiography using tritiated thymidine has shown that cell division of transplanted OPCs does occur [85], hence this must be the reason for the extensive areas of myelination seen at transplant sites. Mitotic signals within the neuropil presumably are responsible, possibly originating from unen-
Fig. 5 Myelination by oligodendrocyte progenitor cells derived from human embryonic stem cells. Three months after transplantation into the shiverer (shi) mouse brain at $\mathrm{P} 0$, grafted cells are found scattered throughout the corpus callosum that are human nuclear antigenpositive and associated with myelin basic protein (MBP)positive myelin (a). The human cells can be seen to be associated with multiple MBP-positive internodes (b). (Reproduced and modified from $\mathrm{Hu}$ et al., 2009:136:1443-1452 [11])
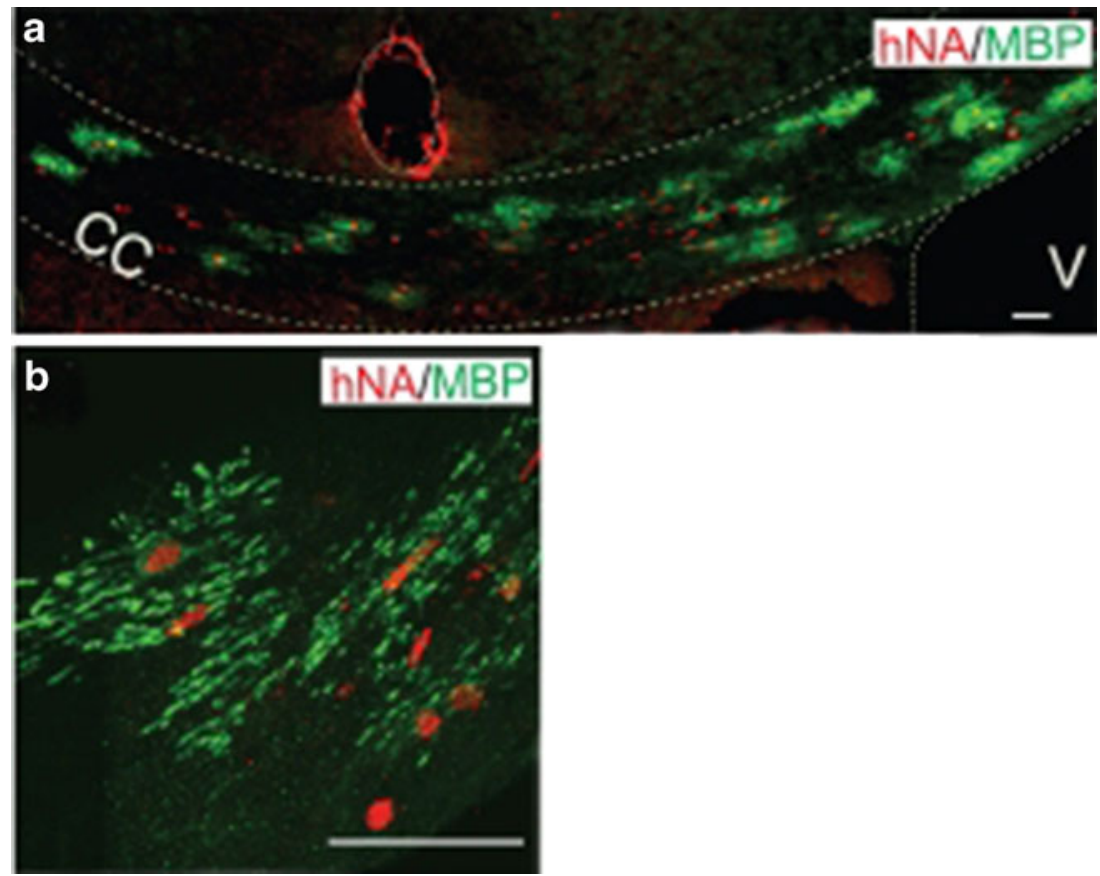
sheathed axons or endogenous glia. It has been shown when OPCs are co-grafted with the neuroblastoma cell line, B-104, which is known to maintain OPCs in a dividing, nondifferentiating state, there is an increase in division of the grafted cells [85]. In addition, when B-104 cells are transplanted distant to the site of grafting of OPCs, the latter migrate toward the B-104 site, suggesting a chemotactic gradient [85]. Hence, it can be concluded that it is possible to both stimulate division of transplanted cells and direct their migration.

To follow cells in vivo, cells can be tracked following their labeling with iron nanoparticles that are detectable by MRI. This has been demonstrated both ex vivo and in vivo in the md rat and migrations of cells followed longitudinally in the les rat spinal cord $[86,87]$. Neural stem cells induced to over-express Olig-2, which were derived from a luciferase-GFP-actin transgenic mouse and transplanted into a mouse fed cuprizone, were detected by bioluminescence imaging in the brain of live mice [88].

\section{Functional Outcome of Transplantation of Cells} into the Myelin Mutants

From a translational standpoint, the key question is whether transplanting stem cells or OPCs into the CNS will have therapeutic significance and improve or restore function and not just result in focal myelin repair. Based on 25 years of research on glial cell transplantation, this can be judged at 3 levels: 1) the myelination resulting from cell therapy results in the formation of normal nodes of Ranvier, 2) there is neurophysiologic evidence of secure conduction in areas of myelination, and 3) extensive myelination resulting from transplants results in behavioral improvement.

\section{Nodes of Ranvier}

Restoration of normal conduction is dependent on the presence of normal nodes. Although it might be expected a priori that myelin made by transplanted cells, which extended along several consecutive internodes would be associated with normal nodes of Ranvier, this required formal proof. Study of the paranodal areas of myelin formed by mouse glial cells transplanted into the $m d$ rat implied that nodes are formed normally after transplantation [22]. Confirmation of this has been documented in 3 recent studies, all of which were following transplantation of cells into the shi mouse. In the first study, adult mouse neural stem cells were injected into shi spinal cord and the area examined 6 weeks later [11]. In areas of MBP-positive compact myelin, the ultrastructure of nodes and paranodes, and the molecular architecture of these areas were studied. EM studies showed the formation of normal paranodal loops. Immunolabeling for $\mathrm{Na}$ and $\mathrm{K}$ channels and Caspr localization at nodes and paranodes was normal [11]. In a similar study in shi mice, but transplanting human glial precursors, 3 areas of the CNS (i.e., the corpus callosum, cervical spinal cord, and optic nerves) were studied in a similar manner to the previous report, and showed normal nodal and paranodal $\mathrm{Na}, \mathrm{K}$, and Caspr localization [55]. This has recently been confirmed in further shi transplants with human cells [83].

\section{Restoration of Conduction}

The first report of restoration of conduction pre-dated the reports showing the production of normal nodes of Ranvier. In this study, $m d$ rats were transplanted with a mixed glial preparation and sacrificed at 15 to 17 days postsurgery. The spinal cord at the site of cell transplant was removed and placed in a brain chamber. The site of engraftment and myelin made by the cells was visible by a naked-eye inspection [89], (Fig. 1), hence it was possible to place stimulating and recording electrodes over both myelinated and nonmyelinated areas of the spinal cord. Areas with myelin repair showed a threefold increase in conduction velocity. Other parameters of normal conduction, such as frequency-response parameters were normal [89]. In the first study of node of Ranvier formation in shi previously noted [79], the authors recorded spinal cord-evoked potentials by stimulating and recording from the dorsal column of the thoracic spinal cord. Nerve conduction velocity was improved through the transplant site, although not restored to normal [79]. Conduction velocity in transplanted shi-rag2 mice was restored close to normal and was significantly faster than nontransplanted mutants [83].

\section{Improvement in the Phenotype Following Transplantation}

The great majority of reports of cell therapy in the myelin mutants have not reported any improvement in behavioral outcome. Two studies, however, have documented phenotypic improvement, both in shi mice. Mice that were transplanted with the mouse neural stem cell line, known as $\mathrm{C} 17.2$ at $\mathrm{P} 0$ were followed for 2 to 8 weeks [90]. The cells, which expressed lacZ, were found to have migrated quite extensively throughout the brain. Myelination was determined by Western blots for MBP, but there was no immunohistochemical demonstration of MBP. EM demonstrated more myelinated axons than normal. It was suggested that the transplanted cells lessened the tremor in the mutant compared to controls using recordings of tail movements [90]. The most definitive proof of restoration of the phenotype, however, comes from the Windrem et al. [55] study of transplantation of human cells into the shirag2 mouse brain (see previously). The mice that survived 
for more than 1 year had fewer seizures, less tremors, improvement in mobility, and so forth. To all intents, these mice were "cured." This result is enormously important for 2 reasons: 1 ) the phenotype of a mutant with global lack of myelin can be reversed, and 2) human progenitor cells are capable of accomplishing this when transplanted as xenografts. Presumably, scaling up of such grafts using similar human cells could lead to even greater myelination of the neonatal human brain.

\section{Transplantation of Cells into the twi Mouse}

As a model of Krabbe disease, a number of studies have been carried out to repair the demyelinating lesions seen in this leukodystrophy using the twi mouse. Because of the complexity of the pathophysiology of the disease, it appears likely that a combined therapeutic approach, perhaps including exogenous cell-based remyelination will be necessary. In most lysosomal disorders, the affected cells can function when the missing enzyme is replaced, even exogenously [6, 91-93]. Therefore, replacing GALC in oligodendrocytes and Schwann cells, either endogenously or exogenously, is critical as a therapeutic approach in Krabbe disease. For example, enzyme replacement by intravenous administration of synthetic GALC has moderately improved the clinicopathology of twi mice [94]. However, the effect is limited because the GALC protein does not cross the blood brain barrier to reach the CNS. The question, therefore, is whether cell-based enzyme replacement therapies in the CNS of twi mice will be successful. When normal OPCs were transplanted into the twi brain, the extent of myelin formed by these cells was not as extensive as seen in shi mice (Kondo and Duncan, unpublished observations). Interestingly, however, these areas showed less active microglial activation and absence of globoid cell-like macrophages, suggesting that the transplanted cells had modulated the host response at the transplant site (Fig. 6). In 1 study, a neural stem cell line genetically modified to overproduce GALC was transplanted into the twi brain [78]. The donor cells appeared to have migrated, proliferated, and finally distributed widely in the brain, although the proportion of donor cells that differentiated into myelinating OLs is unclear. Even though the twi mice is a model of severe demyelination, a considerable amount of endogenous myelin remains in the nervous system (Fig. 7a-d). Therefore, the use of an appropriate marker is necessary to identify donor-cell derived myelin. We found it beneficial to use OPCs derived from CNP-GFP transgenic mice, in which the CNP promoter drives OL specific GFP expression [95], and thus further immunohistochemical demonstration of OLs is not required [6] (Fig. 7e,f).

Atlhough the local transplantation of myelination competent cells is a powerful experimental approach, its clinical limitation in Krabbe disease will be the need to promote cell migration throughout the entire nervous system, including the CNS and PNS. To date, such global migration of exogenous cells, although not myelin-producing cells, has been achieved by bone marrow transplantation (BMT) and umbilical cord blood transplantation (UCBT). We have shown such migration in twi mice following BMT (Fig. 7g-n) (Kondo and Duncan, unpublished). Indeed BMT [96] and UCBT [97] have been performed in patients and proven beneficial, although these therapies have minimal effects on symptomatic patients. Macrophages derived from the BMT
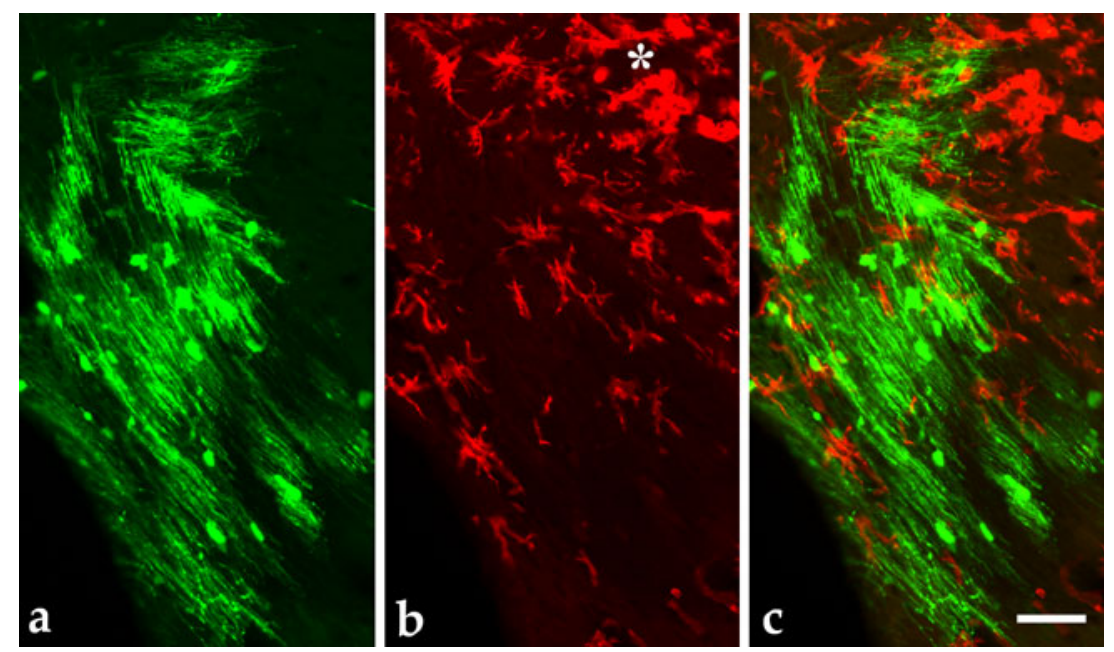

Fig. 6 Normal donor oligodendrocytes subsides host inflammation. The hippocampal fimbria of a 45-day-old twitcher (twi) mouse transplanted with CNP-green fluorescent protein oligodendrocyte progenitor cells at P10 (a). Without engraftment, the white matter of twi mice accumulates a number of macrophages intensely immunoreactive for CD45 $\left({ }^{*} \mathbf{b}\right)$. However, microglia/macrophages are scarce or less active in the engrafted area as evidenced by the donor-derived oligodendrocytes and myelin (c). Scale bar, $50 \mu \mathrm{m}$ 


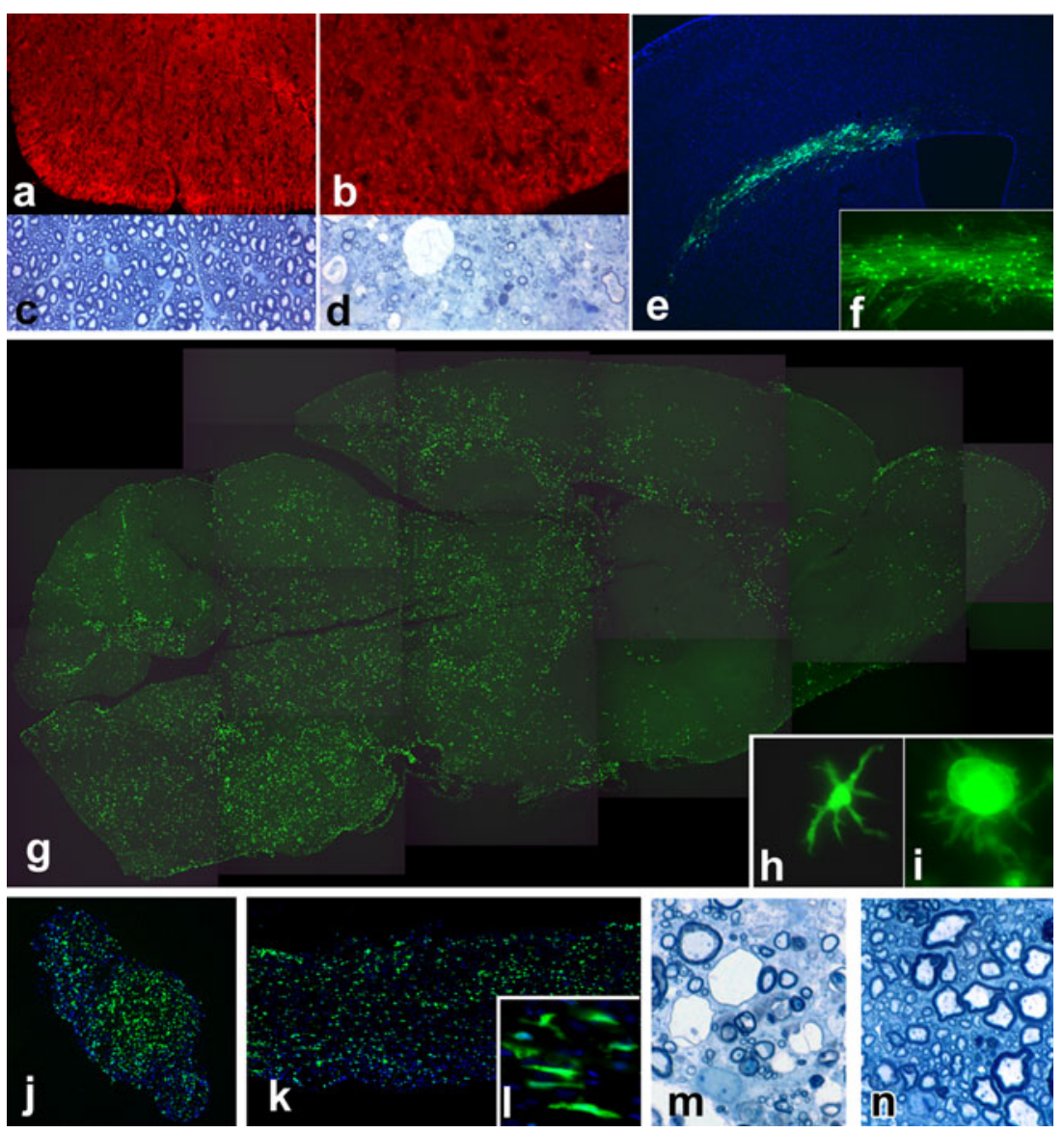

Fig. 7 Transplantation studies in twitcher ( $t w i)$ mice. (a-d) Immunohistochemical staining for myelin basic protein (a, b) and toluidine blue myelin staining $(\mathbf{c}, \mathbf{d})$ in the ventral white matter of the cervical spinal cord from wild-type control (a, c) and twi (b, d) mice at P45. Note that some myelin basic protein (MBP) immunoreactivity, as well as a number of myelinated axons remains even at a moribund stage of twi mice, requiring a proper marker to identify transplanted cells. Punched out MBP-negative areas in (b) correspond to macrophages. (e-f) galactocerebrosidase competent primary oligodendrocyte progenitor cells were cultured from the neonatal brain of CNP-green fluorescent protein (GFP) transgenic mice and transplanted into the corpus callosum of twitcher (twi) pups at $\mathrm{P} 1$ to $\mathrm{P} 3$. CNP promoterdriven GFP expression identifies the donor-derived myelin and oligodendrocytes in the brain of twi mice at P45 (e). Note that the cells have only migrated moderately in the white matter. Donor-

and UCBT infiltrate the donor nervous system and provide neighboring myelinating cells with intact GALC [6, 91, 92]. We demonstrate that transplanting twi cells into the shi mouse, lead to their rescue in vivo through the uptake of endogenous GALC, thus providing proof that this approach is translationally significant. Modifying these cells to allow better enzyme replacement could be a promising approach in treating symptomatic patients. Recently, for instance, enhancing GALC expression by lentiviral gene transduction in hematopoietic stem cells prior to their transplantation into twi mice has been reported, which moderately enhanced the effect of BMT [98]. derived myelin (diffuse green) and oligodendrocytes (intense green) are demonstrated in the inset (f) at higher magnification. (g-n) Donorderived GFP + cells (green) in the nervous system of twi mice after bone marrow transplantation (BMT). The sagittal view of the brain shows that the white matter is the predilection site of migration $(\mathrm{g})$. These GFP + infiltrating cells are of the monocyte lineage and show a branched morphology (h, cerebellar cortex) and a "globoid"-like morphology (I, cerebellar peduncle) at higher magnification. A transverse (j) and a longitudinal section $(\mathbf{k})$ of the sciatic nerve demonstrate GFP + macrophages infiltrated in the peripheral nervous system. An enlarged image of macrophages from $(\mathbf{k})$ is shown in the inset (l). Blue in (j-i) is 4'-6-Diamidino-2-phenylindole counterstaining. Toluidine blue staining of the ventral white matter of the cervical spinal cord in untreated-twi (m) and twi mice 5 weeks after BMT (n) demonstrate an improvement in myelination by BMT

\section{Cells that have been Transplanted in the Myelin Mutants}

Practically all stages of the developmental lineage of the OL have been transplanted into the myelin mutants (as recently reviewed) [99-102]. It is likely that the best cells for myelin repair are those at the more immature stage of the lineage. Thus, neural stem cells, OPCs, and perhaps very immature OLs will be the choice. Although OPCs and OLs can be derived from dissociated cell preparations from the freshly isolated CNS, the more utilized technique is to culture the cells as free-floating preparations, either as 
neural stem cell neurospheres [103] or OPC oligospheres [104-106]. The former can give rise to neurons, astrocytes, and OLs on withdrawal of the growth factors basic fibroblast growth factor (bFGF) and epidermal growth factor (EGF) [103]. However, few OLs are derived from these cells in vitro, but when transplanted into a dysmyelinated background they can generate large numbers of myelinating OLs [80, 107, 108]. Hence, it appears that cues in the milieu promote this oligodendrogenic switch and/or factors in the culture inhibit OL differentiation. If the growth factors, bFGF and EGF are switched slowly for B104-conditioned media, neurospheres can be converted in vitro into pure collections of OPC oligospheres that will differentiate appropriately in culture to mature, membrane-bearing, myelin gene expressing OLs (Fig. 8) [105, 106]. Oligospheres can be derived directly from dissociated striatum and grown in the presence of B-104 conditioned medium [104].

A similar switch from neurospheres to oligospheres has not been successful with human cells, confirming the difference in molecular signals between human and animal cells (Zhang, unpublished data). This has been successfully demonstrated with mouse embryonic stem cells (ESCs) that can be differentiated into neural stem cells that will give rise to myelinating cells on transplantation into the $m d$ rat [109]. These cells are now commonly used in transplantation experiments, being easy to transduce with a variety of genes. The current hope is that human OPCs can be similarly derived from ESCs. The derivation and use of human ESC lines, however, is associated with lingering ethical difficulties. In addition, the generation of a large population of OLs from human ESCs has proven a technical challenge for most laboratories, with the exception of Nistor et al. [110] who used a novel selection method of embryoid bodies and retinoic acid to promote neural differentiation and reported a purity of as much as 95\% OLs in their cultures. Hu et al. [111] reported considerably restricted OL differentiation and highlighted the importance of sonic hedgehog (SHH) in inducing human precursor cells along the OPC differentiation process. They further discovered that expansion of Olig2+/ $\mathrm{Nkx} 2.2+$ pre-OPCs with FGFs inhibits OPC specification through downregulation of SHH signaling [111]. This finding highlights the similarity and difference between human and rodents in OPC specification. It also explains why FGF-expanded human neurospheres rarely convert to OPCs. When these cells were transplanted into shi, they showed patches of MBP-positive areas and human nuclear antigen-positive cells in the corpus callosum (Fig. 6). However, the future may lie with induced pluripotent stem cells (iPSCs), as these cells can be generated on a patient basis by culturing fibroblasts from a skin biopsy and used as autologous grafts following their reprogramming back to an embryonic-like state and then differentiation to a neural lineage [112]. Indeed, OPCs and immature OLs have been derived from human iPSCs in such a fashion, albeit technical issues need to be improved for more efficient OPC generation [113]. However, there are apparent differences between ESCs and iPSCs [113] that suggest the effort should proceed with both cell types to define the best and safest source of myelinating OLs. In addition, a recent study of transplantation of mouse iPSCs has raised a caution that even autologous cells may generate an immune response in the recipient [114].

Greater success to date in demonstrating the myelinating capability of cultured human OPCs has come from the fetal and adult brain using immunomagnetic sorting with antibodies to the Poly-Sialated Neural Cell Adhesion Molecule (PSA-NCAM) and A2B5, surface antigens that are present
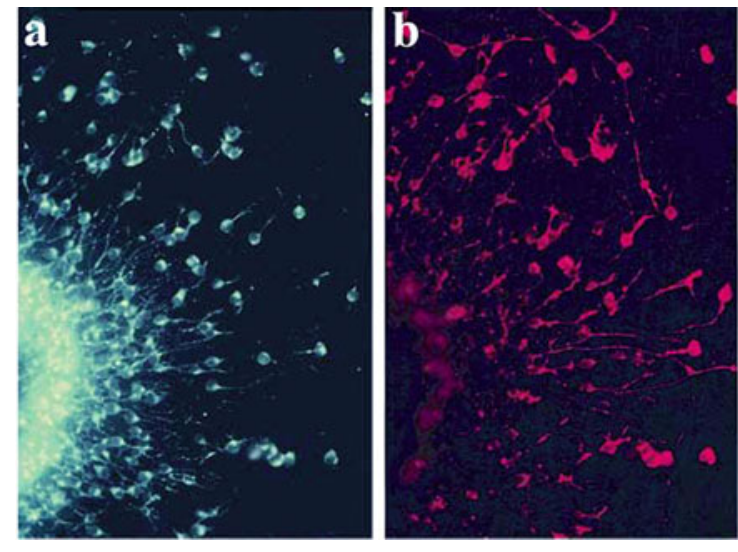

Fig. 8 Oligodendrocyte development in vitro from oligospheres. Representative outgrowth and differentiation of oligodendrocyte progenitor cells from an oligosphere derived from canine striatum. Cells in the oligosphere and those during early migration are Platelet Derived Growth Factor Receptor (PDGFR)- $\alpha$ positive (a), whereas only those that have
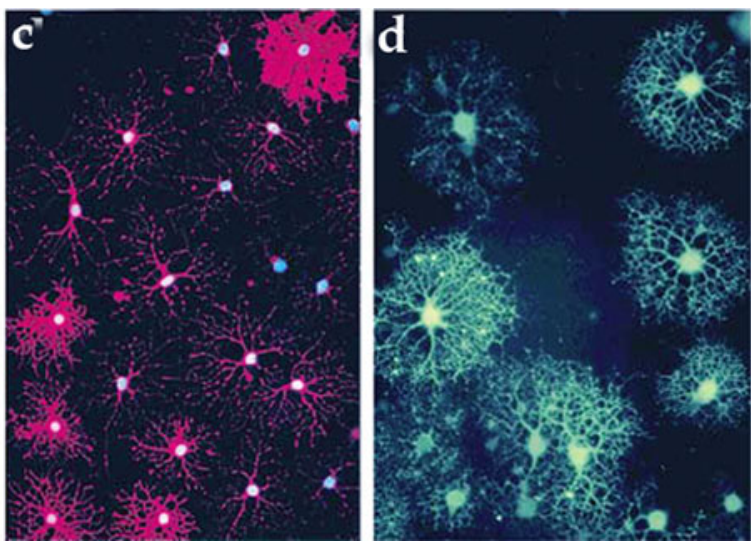

left the sphere are positive for A2B5 (b). In the presence of $0.5 \%$ fetal bovine serum, cells start to differentiate into $\mathrm{O} 1$ positive early oligodendrocytes (OLs) (c) at 4 days in vitro then at 6 days in vitro, express MBP (d), and have the highly branched, membrane-producing appearance of mature OLs. (Modified from Zhang et al, 1998) 
at different stages of neural and glial differentiation [115]. Purified preparations were transplanted into the shi mouse and cells from both fetal and adult sources myelinated shi axons, although paradoxically, adult cells myelinated more efficiently and faster than fetal cells [115]. In a recent study, the gliogenic and myelinating capacity of human neural progenitors from different areas of the brain of the first trimester fetus were investigated, and the oligodendrogenic potential of cells from the ventral telencephalon at 7.5 weeks of gestation demonstrated on transplantation into the shi mouse [83]

\section{Conclusions}

There is optimism that cell replacement therapies will become a therapeutic approach in the leukodystrophies in the near future. Each disease may take a different approach or combined approaches to treatment. A cautionary note will be that exogenous cell therapy will only be successful if there is sufficient numbers of axons surviving to be remyelinated. This might be best evaluated by contemporary MRI, and treatment instigated at a sufficiently early stage of the disease prior to axon loss. In PMD, the ability to deliver large numbers of OPCs at multiple sites and more than 1 occasion, may make it the most straightforward of the leukodystrophies to treat. In Krabbe disease and MLD, cell therapy may be part of a complex treatment strategy that will repair the brain and/or supply the missing enzyme to endogenous OLs and Schwann cells in a global fashion. Defining these therapies in appropriate animal models with some outcome measure (or measures) of success will be a prelude to instigating clinical trials.

Acknowledgments The authors are grateful to all the past members of the Duncan laboratory who contributed to the studies cited here. Currently, this work is partially supported by the National Multiple Sclerosis Society (TR3761), the Boespflug Foundation, The Myelin Project, and the Elizabeth Elser Doolittle Trust. We thank Abigail Radcliff for her expert preparation of the manuscript.

There is no real or perceived conflict of interest. Full conflict of interest disclosure is available in the electronic supplementary material for this article.

\section{References}

1. Costello DJ, Eichler AF, Eichler FS. Leukodystrophies: classification, diagnosis, and treatment. Neurologist 2009;15:319-328.

2. Zhang SC, Duncan ID. Remyelination and restoration of axonal function by glial cell transplantation. Prog Brain Res 2000;127:515-533.

3. Franklin RJ, ffrench-Constant C. Remyelination in the CNS: from biology to therapy. Nat Rev Neurosci 2008;9:839-855.

4. Irvine KA, Blakemore WF. Remyelination protects axons from demyelination-associated axon degeneration. Brain 2008;131:1464 1477 .
5. Huang JK, Franklin RJ. Regenerative medicine in multiple sclerosis: Identifying pharmacological targets of adult neural stem cell differentiation. Neurochem Int 2011;59(3):329-332.

6. Kondo Y, Wenger DA, Gallo V, Duncan ID. Galactocerebrosidasedeficient oligodendrocytes maintain stable central myelin by exogenous replacement of the missing enzyme in mice. Proc Natl Acad Sci U S A 2005;102:18670-18675.

7. Blakemore WF, Eames RA. Remyelination in the spinal cord of the cat following intraspinal injections of lysolecithin. J Neurol Sci 1977;33:31-43.

8. Blakemore WF. Ethidium bromide induced demyelination in the spinal cord of the cat. Neuropathol Appl Neurobiol 1982;8:365375.

9. Blakemore WF, Patterson RC. Suppression of remyelination in the CNS by X-irradiation. Acta Neuropathologica 1978;42:105113.

10. Mason JL, Toews A, Hostettler JD, et al. Oligodendrocytes and progenitors become progressively depleted within chronically demyelinated lesions. Am J Pathol 2004;164:1673-1682.

11. Griffiths IR. Myelin mutants: Model systems for the study of normal and abnormal myelination. BioEssays 1996;18:789-797.

12. Duncan ID. Inherited disorders of myelination of the central nervous system. In: Ransom BR, Kettenmann HR, eds. Neuroglial Cells. Cambridge: Oxford University Press, 1995:990-1009.

13. Griffiths IR, Schneider A, Anderson JM, Nave KA. Transgenic and natural mouse models of proteolipid protein (PLP)-related dysmyelination and demyelination. Brain Pathol 1995;5:275281.

14. Hodes ME, Woodward K, Spinner NB, et al. Additional copies of the proteolipid protein gene causing Pelizaeus-Merzbacher disease arise by separate integration into the $\mathrm{X}$ chromosome. Am J Hum Genet 2000;67:14-22.

15. Mimault C, Giraud G, Courtois V, et al. Proteolipoprotein gene analysis in 82 patients with sporadic Pelizaeus-Merzbacher disease: Duplications, the major cause of the disease, originate more frequently in male germ cells, but point mutations do not. Am J Hum Genet 1999;65:360-369.

16. Bradl $\mathrm{M}$, Bauer $\mathrm{J}$, Inomata $\mathrm{T}$, et al. Transgenic Lewis rats overexpressing the proteolipid protein gene: myelin degeneration and its effect on $\mathrm{T}$ cell-mediated experimental autoimmune encephalomyelitis. Acta Neuropathol(Berl) 1999;97:595-606

17. Mayer J, Larsen E, Duncan I. Characterization of the PLPoverexpressing transgenic rat, a model for the connatal form of Pelizaeus-Merzbacher disease. Neurobiol Dis 2010;44(2):231-238.

18. Jackson KF, Duncan ID. Cell kinetics and cell death in the optic nerve of the myelin deficient rat. J Neurocytol 1988;17:657-670.

19. Csiza CK, de Lahunta A. Myelin deficiency (md): a neurologic mutant in the Wistar rat. Am J Pathol 1979;95:215-224.

20. Wolf NI, Sistermans EA, Cundall M, et al. Three or more copies of the proteolipid protein gene PLP1 cause severe PelizaeusMerzbacher disease. Brain 2005;128(Pt 4):743-751.

21. Duncan ID, Hammang JP, Jackson KF, Wood PM, Bunge RP, Langford LA. Transplantation of oligodendrocytes and Schwann cells into the spinal cord of the myelin-deficient rat. J Neurocytol 1988;17:351-360.

22. Rosenbluth J, Liu Z, Guo D, Schiff R. Myelin formation by mouse glia in myelin-deficient rats treated with cyclosporine. $\mathrm{J}$ Neurocytol 1993;22:967-977.

23. Tontsch U, Archer DR, Dubois-Dalcq M, Duncan ID. Transplantation of an oligodendrocyte cell line leading to extensive myelination. Proc Natl Acad Sci U S A 1994;91:11616-11620.

24. Wenger D, Suzuki K, Suzuki Y, Suzuki K. Galactosylceramide lipidosis. Globoid cell leukodystrophy (Krabbe disease). In: Scriver C, Beaudet A, Sly W, et al, eds. The Metabolic and Molecular Bases of Inherited Disease, 8th ed. New York: McGraw-Hill, 2001:3669-3694 
25. Hess B, Saftig P, Hartmann D, et al. Phenotype of arylsulfatase A-deficient mice: relationship to human metachromatic leukodystrophy. Proc Natl Acad Sci U S A 1996;93:93(25):1482114826.

26. Biffi A, Capotondo A, Fasano S, et al. Gene therapy of metachromatic leukodystrophy reverses neurological damage and deficits mice. J Clin Invest 2006;116:3070-3082.

27. Givogri MI, Bottai D, Zhu HL, et al. Multipotential neural precursors transplanted into the metachromatic leukodystrophy brain fail to generate oligodendrocytes but contribute to limit brain dysfunction. Dev Neurosci 2008;30:340-357.

28. Moser HW. Adrenoleukodystrophy: phenotype, genetics, pathogenesis and therapy. Brain 1997;120:1485-1508.

29. Dubois-Dalcq M, Feigenbaum V, Aubourg P. The neurobiology of X-linked adrenoleukodystrophy, a demyelinating peroxisomal disorder. Trends Neurosci 1999;22:4-12.

30. Powers JM. The pathology of peroxisomal disorders with pathogenetic considerations. J Neuropathol Exp Neurol 1995;54:710-719.

31. Ferrer I, Aubourg P, Pujol A. General aspects and neuropathology of X-linked adrenoleukodystrophy. Brain Pathol 2010;20:817-830.

32. Kassmann CM, Lappe-Siefke C, Baes M, et al. Axonal loss and neuroinflammation caused by peroxisome-deficient oligodendrocytes. Nat Genet 2007;39:969-976.

33. Hagemann TL, Connor JX, Messing A. Alexander diseaseassociated glial fibrillary acidic protein mutations in mice induce Rosenthal fiber formation and a white matter stress response. J Neurosci 2006;26:11162-11173.

34. Matalon R, Rady PL, Platt KA, et al. Knock-out mouse for Canavan disease: a model for gene transfer to the central nervous system. J Gene Med 2000;2:165-175.

35. Surendran S, Campbell GA, Tyring SK, Matalon R. Aspartoacylase gene knockout results in severe vacuolation in the white matter and gray matter of the spinal cord in the mouse. Neurobiol Dis 2005;18:385-389.

36. Kitada K, Akimitsu T, Shigematsu Y, et al. Accumulation of Nacetyl-L-aspartate in the brain of the tremor rat, a mutant exhibiting absence-like seizure and spongiform degeneration in the central nervous system. J Neurochem 2000;74:2512-2519.

37. Li FY, Cuddon PA, Song J, et al. Canine spongiform leukoencephalomyelopathy is associated with a missense mutation in cytochrome b. Neurobiol Dis 2006;21:35-42.

38. Oldfors A, Tulinius M. Mitochondrial encephalomyopathies. J Neuropathol Exp Neurol 2003;62:217-227.

39. Surendran S, Shihabuddin LS, Clarke J, et al. Mouse neural progenitor cells differentiate into oligodendrocytes in the brain of a knockout mouse model of Canavan disease. Dev Brain Res 2004; 153:19-27.

40. van der Knaap M, Pronk J, Scheper G. Vanishing white matter disease. Lancet Neurol 2006;5:413-423.

41. Garbern JY, Yool DA, Moore GJ, et al. Patients lacking the major CNS myelin protein, proteolipid protein 1, develop lengthdependent axonal degeneration in the absence of demyelination and inflammation. Brain 2002;125:551-561.

42. Trapp BD, Nave KA. Multiple sclerosis: an immune or neurodegenerative disorder? Annu Rev Neurosci 2008;31:247269.

43. Simons R, Riordan JR. The myelin-deficient rat has a single base substitution in the third exon of the myelin proteolipid protein gene. J Neurochem 1990;54:1079-1081.

44. Lipsitz D, Goetz BD, Duncan ID. Apoptotic glial cell death and kinetics in the spinal cord of the myelin-deficient rat. J Neurosci Res 1998;51:497-507.

45. Duncan ID, Hammang JP, Trapp BD. Abnormal compact myelin in the myelin-deficient rat: Absence of proteolipid protein correlates with a defect in the intraperiod line. Proc Natl Acad Sci U S A 1987;84:6287-6291.

46. Learish RD, Brüstle O, Zhang SC, Duncan ID. Intraventricular transplantation of oligodendrocyte progenitors into a fetal myelin mutant results in widespread formation of myelin. Ann Neurol 1999;46:716-722.

47. Duncan ID, Nadon NL, Hoffman RL, Lunn KF, Csiza CK, Wells MR. Oligodendrocyte survival and function in the long-lived strain of the myelin deficient rat. J Neurocytol 1995;24:745-762.

48. Duncan ID, Griffiths IR. Shaking pups: A disorder of central myelination in the Spaniel dog. III. Quantitative aspects of glia and myelin in the spinal cord and optic nerve. Neuropathol Appl Neurobiol 1983;9:355-368.

49. Griffiths IR, Duncan ID, McCulloch M, Harvey MJA. Shaking pups: A disorder of central myelination in the Spaniel dog. I Clinical, genetic and light microscopical observations. J Neurol Sci 1981;50:423-433.

50. Nadon NL, Duncan ID, Hudson LD. A point mutation in the proteolipid protein gene of the "shaking pup" interrupts oligodendrocyte development. Development 1990;110:529-537.

51. Wu Y-C, Field AS, Duncan ID, Samsonov AA, Alexander AL. High $b$-value and diffusion tensor imaging in a canine model of dysmyelination and brain maturation. Neuroimage 2011;58(3):829 837.

52. Archer DR, Cuddon PA, Lipsitz D, Duncan ID. Myelination of the canine central nervous system by glial cell transplantation: a model for repair of human myelin disease. Nat Med 1997;3:54-59.

53. Mikoshiba K, Aruga J, Ikenaka K, Okano H, Martenson RE. Shiverer and allelic mutant mld mice. In: Myelin: Biology and Chemistry. Boca Raton: CRC Press, 1992:723-744.

54. Lachapelle F, Gumpel M, Baulac M, Jacque C, Duc P, Baumann N. Transplantation of CNS fragments into the brain of shiverer mutant mice: extensive myelination by implanted oligodendrocytes. I. Immunohistochemical studies. Dev Neurosci $1983 ; 6: 325-334$

55. Windrem MS, Schanz SJ, Guo M, et al. Neonatal chimerization with human glial progenitor cells can both remyelinate and rescue the otherwise lethally hypomyelinated shiverer mouse. Cell Stem Cell 2008;2:553-565.

56. O'Connor LT, Goetz BD, Kwiecien JM, Delaney KH, Fletch AL, Duncan ID. Insertion of a retrotransposon into the myelin basic gene causes CNS dysmyelination in the Long Evans shaker ( les ) rat. J Neurosci 1999;19:3404-3413.

57. Kwiecien JM, O'Connor LT, Goetz BD, Delaney KH, Fletch AL, Duncan ID. Morphological and morphometric studies of the dysmyelinating mutant, the Long Evans shaker rat. J Neurocytol 1998;27:581-591.

58. Zhang SC, Goetz BD, Carr, JL, Duncan ID. Reactive microglia in dysmyelination and demyelination. GLIA 2001;34:101-109

59. Duncan ID, Lunn KF, Holmgren B, Urba-Holmgren R, Brignolo-Holmes L. The taiep rat: A myelin mutant with an associated oligodendrocyte microtubular defect. J Neurocytol 1992;21:870-884.

60. Song J, O'Connor LT, Yu W, Baas PW, Duncan ID. Microtubule alterations in cultured taiep rat oligodendrocytes lead to deficits in myelin membrane formation. J Neurocytol 1999;28:671-683.

61. O'Connor LT, Goetz BD, Couve E, Song J, Duncan ID. Intracellular distribution of myelin protein gene products is altered in oligodendrocytes of the taiep rat. Mol Cell Neurosci 2000;16:396-407.

62. Song J, Goetz BD, Baas PW, Duncan ID. Cytoskeletal reorganization during the formation of oligodendrocyte processes and branches. Mol Cell Neurosci 2001;17:624-636.

63. Song J, Carson JH, Barbarese E, Li FY, Duncan ID. RNA transport in oligodendrocytes from the taiep mutant rat. Mol Cell Neurosci 2003;24:926-938. 
64. Li FY, Song J, Duncan ID. Mapping of taiep rat phenotype to rat Chromosome 9. Mamm Genome 2003;14:703-705.

65. Duchen LW, Eicher EM, Jacobs JM, Scaravilli F, Teixeira F. Hereditary leucodystrophy in the mouse: the new mutant twitcher. Brain 1980;103:695-710.

66. Sakai N, Inui K, Tatsumi N, et al. Molecular cloning and expression of cDNA for murine galactocerebrosidase and mutation analysis of the twitcher mouse, a model of Krabbe's disease. J Neurochem 1996;66:1118-1124.

67. Rafi MA, Rao HZ, Passini MA, et al. AAV-mediated expression of galactocerebrosidase in brain results in attenuated symptoms and extended life span in murine models of globoid cell leukodystrophy. Mol Ther 2005;11:734-744.

68. Kondo Y, Adams JM, Vanier MT, Duncan ID. Macrophages counteract demyelination in a mouse model of globoid cell leukodystrophy. J Neurosci 2011;31:3610-3624.

69. Taniike M, Suzuki K. Spacio-temporal progression of demyelination in twitcher mouse: With clinico-pathological correlation. Acta Neuropathol 1994;88:228-236.

70. Victoria T, Rafi MA, Wenger DA. Cloning of the canine GALC cDNA and identification of the mutation causing globoid cell leukodystrophy in West Highland White and Cairn terriers. Genomics 1996;33:457-462.

71. Capucchio MT, Prunotto M, Lotti D, et al. Krabbe's disease in two West Highland White terriers. Clin Neuropathol 2008;27:295-301.

72. Sigurdson CJ, Basaraba RJ, Mazzaferro EM, Gould DH. Globoid cell-like Leukodystrophy in a domestic longhaired cat. Vet Pathol 2002;39:494-496.

73. Baskin GB, Ratterree M, Davison BB, et al. Genetic galactocerebrosidase deficiency (globoid cell leukodystrophy, Krabbe disease) in Rhesus monkeys (macaca mulatta). Lab Anim Sci 1998;48:476-482.

74. Gumpel M, Lachapelle F, Baumann N, Björklund A, Stenevi U. Central nervous tissue transplantation into mouse brain: differentiation of myelin from transplanted oligodendrocytes. In: Neural Grafting in the Mammalian CNS: Elsevier Science Publishers, B.V., 1985:151-158.

75. Gumpel M, Gout O. Myelination and remyelination in the central nervous system by transplanted oligodendrocytes using the shiverer model. Dev Neurosci 1989;11:132-139.

76. Gansmuller A, Lachapelle F, Baron-Van Evercooren A, Hauw JJ, Baumann N, Gumpel M. Transplantations of newborn CNS fragments into the brain of shiverer mutant mice: extensive myelination by transplanted oligodendrocytes. II. Electron microscopic study. Dev Neurosci 1986;8:197-207

77. Schiff R, Rosenbluth J, Dou WK, Liang WL, Moon D. Distribution and morphology of transgenic mouse oligodendroglial- lineage cells following transplantation into normal and myelin-deficient rat CNS. J Comp Neurol 2002;446:46-57.

78. Taylor RM, Lee JP, Palacino JJ, et al. Intrinsic resistance of neural stem cells to toxic metabolites may make them well suited for cell non-autonomous disorders: evidence from a mouse model of Krabbe leukodystrophy. J Neurochem 2006;97:1585-1599.

79. Eftekharpour E, Karimi-Abdolrezaee S, Wang J, El Beheiry H, Morshead C, Fehlings MG. Myelination of congenitally dysmyelinated spinal cord axons by adult neural precursor cells results in formation of nodes of Ranvier and improved axonal conduction. J Neurosci 2007;27:3416-3428

80. Mothe AJ, Kulbatski I, Parr A, Mohareb M, Tator CH. Adult spinal cord stem/progenitor cells transplanted as neurospheres preferentially differentiate into oligodendrocytes in the adult rat spinal cord. Cell Transplant 2008;17:735-751.

81. Foote AK, Blakemore WF. Inflammation stimulates remyelination in areas of chronic demyelination. Brain 2005;128:528-539.
82. Mitome M, Low HP, van den Pol A, et al. Towards the reconstruction of central nervous system white matter using neural precursor cells. Brain 2001;124:2147-2161.

83. Buchet D, Garcia C, Deboux C, Nait-Oumesmar B, Baron-Van Evercooren A. Human neural progenitors from different foetal forebrain regions remyelinate the adult mouse spinal cord. Brain 2011;134:1168-1183.

84. Zhang SC, Wagner D, Duncan ID. Acute death of grafted oligodendroglial progenitors. Soc for Neurosci 1999;25:215.

85. Milward EA, Zhang SC, Zhao M, et al. Enhanced proliferation and directed migration of oligodendroglial progenitors co-grafted with growth factor-secreting cells. GLIA 2000;32:264-270.

86. Bulte JWM, Douglas T, Witwer B, et al. Magnetodendrimers allow endosomal magnetic labeling and in vivo tracking of stem cells. Nat Biotechnol 2001;19:1141-1147.

87. Bulte JWM, Zhang SC, van Gelderen P, et al. Neurotransplantation of magnetically labeled oligodendrocyte progenitors: MR tracking of cell migration and myelination. Proc Natl Acad Sci 1999;96(26):15256-15261.

88. Sher F, van Dam G, Boddeke E, Copray S. Bioluminescence imaging of Olig2-neural stem cells reveals improved engraftment in a demyelination mouse model. Stem Cells 2009;27:15821591.

89. Utzschneider DA, Archer DR, Kocsis JD, Waxman SG, Duncan ID. Transplantation of glial cells enhances action potential conduction of amyelinated spinal cord axons in the myelindeficient rat. Proc Natl Acad Sci U S A 1994;91:53-57.

90. Yandava BD, Billinghurst LL, Snyder EY. "Global" cell replacement is feasible via neural stem cell transplantation: Evidence from the dysmyelinated shiverer mouse brain. Proc Natl Acad Sci USA 1999;96:7029-7034.

91. Scaravilli F, Suzuki K. Enzyme replacement in grafted nerve of twitcher mouse. Nature 1983;305:713-715.

92. Scaravilli F, Jacobs JM. Improved myelination in nerve grafts from the leucodystrophic twitcher into trembler mice: Evidence for enzyme replacement. Brain Res 1982;237:163-172.

93. Luddi A, Volterrani M, Strazza M, et al. Retrovirus-mediated gene transfer and galactocerebrosidase uptake into twitcher glial cells results in appropriate localization and phenotype correction. Neurobiol Dis 2001;8:600-610.

94. Lee WC, Courtenay A, Troendle FJ, et al. Enzyme replacement therapy results in substantial improvements in early clinical phenotype in a mouse model of globoid cell leukodystrophy. FASEB J 2005;19(11):1549-1551.

95. Yuan X, Chittajallu R, Belachew S, Anderson S, McBain CJ, Gallo V. Expression of the green fluorescent protein in the oligodendrocyte lineage: a transgenic mouse for developmental and physiological studies. J Neurosci Res 2002;70:529-545.

96. Krivit W, Shapiro EG, Peters C, et al. Hematopoietic stem-cell transplantation in globoid-cell leukodystrophy. $\mathrm{N}$ Engl J Med 1998;338:1119-1126.

97. Escolar ML, Poe MD, Provenzale JM, et al. Transplantation of umbilical-cord blood in babies with infantile Krabbe's disease. New Engl J Med 2005;352:2069-2081.

98. Gentner B, Visigalli I, Hiramatsu H, et al. Identification of hematopoietic stem cell-specific miRNAs enables gene therapy of globoid cell leukodystrophy. Sci Transl Med 2010;2 (58):58ra84.

99. Buchet D, Baron-Van Evercooren A. In search of human oligodendroglia for myelin repair. Neurosci Lett 2009;456:112119

100. Duncan ID. Oligodendrocytes and stem cell transplantation: their potential in the treatment of leukoencephalopathies. J Inherit Metab Dis 2005;28:357-368.

101. Ben-Hur T, Goldman SA. Prospects of cell therapy for disorders of myelin. Ann N Y Acad Sci 2008;1142:218-249. 
102. Duncan ID, Goldman S, Macklin WB, Rao M, Weiner LP, Reingold SC. Stem cell therapy in multiple sclerosis: promise and controversy. Mult Scler 2008;14:541-546.

103. Reynolds BA, Weiss S. Generation of neurons and astrocytes from isolated cells of the adult mammalian central nervous system. Science 1992;255:1707-1710.

104. Avellana-Adalid V, Nait-Oumesmar B, Lachapelle F, Baron-Van Evercooren A. Expansion of rat oligodendrocyte progenitors into proliferative "oligospheres" that retain differentiation potential. J Neurosci Res 1996;45:558-570

105. Zhang SC, Lipsitz D, Duncan ID. Self-renewing canine oligodendroglial progenitor expanded as oligospheres. J Neurosci Res 1998;54:181-190.

106. Zhang SC, Lundberg C, Lipsitz D, O’Connor LT, Duncan ID. Generation of oligodendroglial progenitors from neural stem cells. J Neurocytol 1998;27:475-489.

107. Hammang JP, Archer DR, Duncan ID. Myelination following transplantation of EGF-responsive neural stem cells into a myelin-deficient environment. Exp Neurol 1997;147:84-95.

108. Mothe AJ, Tator CH. Transplanted neural stem/progenitor cells generate myelinating oligodendrocytes and Schwann cells in spinal cord demyelination and dysmyelination. Exp Neurol 2008;213:176-190.

109. Brüstle O, Jones KN, Learish RD, et al. Embryonic stem cellderived glial precursors: a source of myelinating transplants. Science 1999;285:754-756.

110. Nistor GI, Totoiu MO, Haque N, Carpenter MK, Keirstead HS. Human embryonic stem cells differentiate into oligodendrocytes in high purity and myelinate after spinal cord transplantation. GLIA 2005;49:385-396.

111. Hu BY, Du ZW, Li XJ, Ayala M, Zhang SC. Human oligodendrocytes from embryonic stem cells: conserved $\mathrm{SHH}$ signaling networks and divergent FGF effects. Development 2009;136:1443-1452.

112. Koch P, Kokaia Z, Lindvall O, Brustle O. Emerging concepts in neural stem cell research: autologous repair and cell-based disease modelling. Lancet Neurol 2009;8:819-829.

113. Hu BY, Weick JP, Yu J, et al. Neural differentiation of human induced pluripotent stem cells follows developmental principles but with variable potency. Proc Natl Acad Sci U S A 2010;107:4335-4340.
114. Zhao T, Zhang ZN, Rong Z, Xu Y. Immunogenicity of induced pluripotent stem cells. Nature 2011;474:212-215.

115. Windrem MS, Roy NS, Wang J, et al. Progenitor cells derived from the adult human subcortical white matter disperse and differentiate as oligodendrocytes within demyelinated lesions of the rat brain. J Neurosci Res 2002;69:966-975.

116. Zhang SC, Ge B, Duncan ID. Adult brain retains the potential to generate oligodendroglial progenitors with extensive myelination capacity. Proc Natl Acad Sci 1999;96:4089-4094.

117. Klugmann M, Schwab MH, Pühlhofer A, et al. Assembly of CNS myelin in the absence of proteolipid protein. Neuron 1997;18:59-70

118. Boison D, Stoffel W. Disruption of the compacted myelin sheath of axons of the central nervous system in proteolipid proteindeficient mice. Proc Natl Acad Sci U S A 1994;91:11709-11713.

119. Windrem MS, Nunes MC, Rashbaum WK, et al. Fetal and adult human oligodendrocyte progenitor cell isolates myelinate the congenitally dysmyelinated brain. NatMed 2004;10:93-97.

120. Lee WC, Tsoi YK, Troendle FJ, et al. Single-dose intracerebroventricular administration of galactocerebrosidase improves survival in a mouse model of globoid cell leukodystrophy. Faseb J 2007;21:2520-2527.

121. Yeager A, Brennan S. Prolonged survival and remyelination after hematopoietic cell transplantation in the twitcher mouse. Science 1984;225:1052-1054.

122. Matzner U, Herbst E, Hedayati KK, et al. Enzyme replacement improves nervous system pathology and function in a mouse model for metachromatic leukodystrophy. Hum Mol Genet 2005; 14:1139-1152.

123. Sevin C, Verot L, Benraiss A, et al. Partial cure of established disease in an animal model of metachromatic leukodystrophy after intracerebral adeno-associated virus-mediated gene transfer. Gene Ther 2007;14:405-414.

124. Matzner U, Hartmann D, Lullmann-Rauch R, et al. Bone marrow stem cell-based gene transfer in a mouse model for metachromatic leukodystrophy: effects on visceral and nervous system disease manifestations. Gene Ther 2002;9:53-63.

125. Lu JF, Lawler AM, Watkins PA, et al. A mouse model for Xlinked adrenoleukodystrophy. Proc Natl Acad Sci U S A 1997;94:9366-9371. 